Original Article

\title{
The reliability of evaluation of hip muscle strength in rehabilitation robot walking training
}

\author{
Qiuchen Huang, PT, PhD ${ }^{1,2)}$, Yue Zhou, $\mathrm{PT}^{1,2)}$, Lili Yu, $\mathrm{PT}^{1,2)}$, Rui Gu, PhD ${ }^{1,3)}$, Yao Cui, $\mathrm{PT}^{1,2)}$, \\ Chunying Hu, $\mathrm{PT}^{1,2)^{*}}$ \\ 1) School of Rehabilitation Medicine, Capital Medical University, China \\ 2) Department of Physical Therapy, China Rehabilitation Research Center: No. 10, North Road, \\ Fengtai District, Beijing 100077, China \\ 3) Department of Orthopedic and Orthopedic Rehabilitation, China Rehabilitation Research Center, \\ China
}

\begin{abstract}
Purpose] The primary purpose of this study was to evaluate the intraclass correlation coefficient in obtaining the torque of the hip muscle strength during a robot-assisted rehabilitation treatment. [Subjects] Twentyfour patients (15 males, 9 females) with spinal cord injury participated in the study. [Methods] The subjects were asked to walk during robot-assisted rehabilitation, and the torque of the muscle strength which was measured at hip joint flexion angles of $-15,-10,-5,0,5,10,15,20,25$, and 30 degrees. [Results] The intraclass correlation coefficient of the torque of the hip muscle strength measured by the rehabilitation training robot was excellent. [Conclusion] Our results show that measurement of torque can be used as an objective assessment of treatment with RAT. Key words: Hip muscle strength, Robot-assisted rehabilitation
\end{abstract}

(This article was submitted May 21, 2015, and was accepted Jul. 6, 2015)

\section{INTRODUCTION}

To recover locomotor ability after spinal injury, various therapies are traditionally used, such as walking training with body weight-supported treadmill training (BWSTT). BWSTT is used in rehabilitation to improve gait function by training a normal gait pattern and for training in a safe environment. However, it is too labor intensive. To perform BWSTT, which entails a high workload even at a very slow speed, patients require the assistance of 2 or more therapists $^{1)}$.

In recent years, robot-assisted rehabilitation (RAT), which simulates the normal walking, has also be adopted to help patients with spinal cord injury. Currently, RAT is widely used during the recovery process. The biggest difference between robot-assisted body weight-supported treadmill training and the existing supported ambulation training is the addition of a mechanical assistant in the former so that alternative steps with both feet can be achieved by the patients. Besides, simulation of the normal walking pattern facilitates input from the peripheral nerve endings; in this manner, the remaining central nervous system can be stimulated so that regeneration of the nerves involved in the

*Corresponding author. Chunying $\mathrm{Hu}$

(E-mail: christinehcy@163.com)

(C)2015 The Society of Physical Therapy Science. Published by IPEC Inc. This is an open-access article distributed under the terms of the Creative Commons Attribution Non-Commercial No Derivatives (by-ncnd) License $<$ http://creativecommons.org/licenses/by-nc-nd/3.0/>. traumatic spinal cord injury can be completed ${ }^{2}$. Recently, some studies have shown that this method has a significant effect on the improvement of response time ${ }^{3)}$.

Several studies have reported that patients with incomplete spinal cord injury (SCI) can recover locomotor function after robot-assisted rehabilitation ${ }^{4)}$. The reason for this improvement in locomotor activity was an adaptation of spinal neuronal networks to physiological proprioceptive inputs ${ }^{5)}$. Strengthening of cortical input might also play an important role in functional recovery of locomotion ${ }^{6}$.

At present, rehabilitation robots are very widely used in clinical practice ${ }^{7)}$. But the treatment effect of rehabilitation robots has only been examined based on activities of daily living (ADL) and other measures ${ }^{8}$. There have been very few mechanical evaluations regarding the kinetics of paralyzed limbs using torque in metric units, especially the real-time intervention effects of walking with a rehabilitation robot.

The primary purpose of this study was to evaluate the intraclass correlation coefficient (ICC) in obtaining the torque of the hip muscle strength during a RAT treatment.

\section{SUBJECTS AND METHODS}

Twenty-four patients ( 15 males, 9 females) with spinal cord injury participated in the study. All subjects had an incomplete injury ranging from level T8 to L2, and each injury occurred during the previous six months. None of the patients had received RAT before. Subject characteristics are detailed in Table 1 . The purpose and procedure of this study were explained to the subjects, and all subjects gave 
informed consent for participation in the study. The study was approved by the Research Ethics Committee of China Rehabilitation Research Center, and the IRB number for this study is 2014-K-005.

The subjects were asked to walk during robot-assisted rehabilitation with an initial training speed of $1.5 \mathrm{~km} / \mathrm{h}$, which was progressively raised to $1.8 \mathrm{~km} / \mathrm{h}$ as quickly as possible while maintaining a gait quality similar to that of a normal healthy human. The body weight suspension system was initiated at $35 \%$, and $70 \%$ guidance force was provided for the participants by the weight suspension system of RAT system.

The robot-assisted rehabilitation walking training was carried out with a rehabilitation training robot (MBZ-CPM1, ManBuZhe [TianJin] Rehabilitation Equipment Co., Ltd., Tianjin, PR China). An adjustable lever arm was attached to the subject's right leg with a padded cuff just proximal to the knee joint. The axis of rotation of the dynamometer arm was positioned just lateral to the femoral epicondyle, and the torque of the muscle strength which was measured at hip joint flexion angles of $-15,-10,-5,0,5,10,15,20,25$, and 30 degrees during the swing phase. The average torque value was measured at each angle when the subject was walking during RAT. Each measurement was made twice, with the measurements being made on different days.

In order to determine the reliability of the torque of the hip muscle strength during the RAT treatment, the ICC for the two measurements of the torque of the hip joint during exercise was examined at each of the angles. The data were analyzed using SPSS Ver. 17.0 for Windows.

\section{RESULTS}

The results for the torque of the hip muscle strength of the 24 subjects are shown in Table 2.

All ICCs (1.1) for the torque of the hip muscle strength

Table 1. Subject characteristics

\begin{tabular}{lc}
\hline & $\mathrm{M} \pm \mathrm{SD}(\mathrm{N}=24)$ \\
\hline Age $(\mathrm{y})$ & $26.3 \pm 5.7$ \\
Height $(\mathrm{cm})$ & $169.4 \pm 8.4$ \\
Weight $(\mathrm{kg})$ & $61.8 \pm 10.4$ \\
\hline
\end{tabular}

were more than 0.75 for the right leg during robot-assisted rehabilitation walking training.

\section{DISCUSSION}

Although robot-assisted walking training is widely used in clinical practice, there is no objective assessment method for it. In the present study, we evaluated the reliability in obtaining the torque of the hip muscle strength during walking training in RAT. The torque of the hip muscle strength measured by the rehabilitation training robot was excellent. Whether we measured flexion or extension, the constriction of the hip muscle strength could be monitored by evaluation with the rehabilitation training robot.

These results indicate that measurements of torque can be used as an objective assessment of treatment with a rehabilitation robot. The hip muscle strength of a patient with a spinal cord injury could also be evaluated during robotassisted rehabilitation walking training. Compared with the previous subjective assessment method, measurement of torque in metric units was intuitional and practicable.

In the clinic, torque could also be used as a real-time measurement and provide feedback to a therapist that could aid in selection of a more effective treatment method. In the present study, the ICC could indicate the consistency between the two measurements, but internal errors could not be expressed. Furthermore, the measurements were carried out by one experimenter on one day, so the reliability of the torque of the hip muscle strength during a RAT treatment would need to be examined again if the measurements were carried out under different conditions.

Future studies are needed to investigate the inter-rater reliability, standard error of measurement, and minimal detectable change in the torque of hip muscle strength during a RAT treatment.

\section{ACKNOWLEDGEMENT}

This paper was supported by the Research on Design Theory and Compliant Control for Underactuated LowerExtremity Rehabilitation Robotic Systems (Code: 51175368; 2012.01-2015.12).

Table 2. Torque of the hip muscle strength (Nm) and ICC

\begin{tabular}{llcccccccccc}
\hline \multicolumn{10}{c}{ Angle of the Right Hip Joint $\left(^{\circ}\right)$} \\
\hline \multirow{2}{*}{ Swing } & 1st time & $16.5 \pm 4.7$ & $19.6 \pm 2.6$ & $2.6 \pm 3.3$ & $3.6 \pm 1.5$ & $4.9 \pm 2.7$ & $15.3 \pm 2.4$ & $11.2 \pm 2.5$ & $13.2 \pm 2.7$ & $22.5 \pm 3.3$ & $34.3 \pm 5.7$ \\
phase & 2nd time & $16.0 \pm 3.9$ & $18.6 \pm 3.1$ & $3.6 \pm 2.2$ & $2.9 \pm 1.7$ & $5.4 \pm 2.2$ & $16.2 \pm 2.7$ & $10.6 \pm 2.7$ & $13.0 \pm 3.1$ & $23.6 \pm 2.9$ & $34.8 \pm 4.3$ \\
& ICC & $0.93^{* *}$ & $0.83^{* *}$ & $0.83^{* *}$ & $0.88^{* *}$ & $0.78^{* *}$ & $0.87^{* *}$ & $0.82^{* *}$ & $0.89^{* *}$ & $0.83^{* *}$ & $0.89^{* *}$ \\
Period & 1st time & $25.3 \pm 6.5$ & $33.8 \pm 10.9$ & $20.5 \pm 7.8$ & $19.2 \pm 5.5$ & $15.7 \pm 8.7$ & $9.5 \pm 7.6$ & $40.9 \pm 12.3$ & $43.72 \pm 8.5$ & $45.2 \pm 10.6$ & $63.4 \pm 14.3$ \\
of & 2nd time & $29.1 \pm 9.1$ & $29.1 \pm 11.2$ & $20.3 \pm 8.6$ & $18.1 \pm 6.9$ & $15.8 \pm 9.2$ & $11.8 \pm 7.6$ & $37.6 \pm 13.2$ & $40.3 \pm 9.7$ & $41.7 \pm 10.9$ & $71.1 \pm 16.9$ \\
support & ICC & $0.79^{* *}$ & $0.83^{* *}$ & $0.93^{* *}$ & $0.87^{* *}$ & $0.82^{* *}$ & $0.83^{* *}$ & $0.88^{* *}$ & $0.87^{* *}$ & $0.89^{* *}$ & $0.89^{* *}$ \\
\hline
\end{tabular}

$* \mathrm{p}<0.05 ; * * \mathrm{p}<0.01$ 


\section{REFERENCES}

1) Anwer S, Equebal A, Palekar TJ, et al.: Effect of locomotor training on motor recovery and walking ability in patients with incomplete spinal cord injury: a case series. J Phys Ther Sci, 2014, 26: 951-953. [Medline] [CrossRef]

2) Dietz V, Colombo G, Jensen L, et al.: Locomotor capacity of spinal cord in paraplegic patients. Ann Neurol, 1995, 37: 574-582. [Medline] [CrossRef]

3) Tang Q, Huang Q, Hu C: Research on design theory and compliant contro for underactuated lower-extremity rehabilitation robotic systems code (51175368); 2012.01-2015.12. J Phys Ther Sci, 2014, 26: 1597-1599. [Medline] [CrossRef]

4) Wirz M, Colombo G, Dietz V: Long term effects of locomotor training in spinal humans. J Neurol Neurosurg Psychiatry, 2001, 71: 93-96. [Medline]
[CrossRef]

5) Davey NJ, Smith HC, Wells E, et al.: Responses of thenar muscles to transcranial magnetic stimulation of the motor cortex in patients with incomplete spinal cord injury. J Neurol Neurosurg Psychiatry, 1998, 65: 80-87. [Medline] [CrossRef]

6) Barbeau H, McCrea DA, O’Donovan MJ, et al.: Tapping into spinal circuits to restore motor function. Brain Res Brain Res Rev, 1999, 30: 27-51. [Medline] [CrossRef]

7) Bae $\mathrm{YH}, \mathrm{Ko} \mathrm{YJ}$, Chang WH, et al.: Effects of robot-assisted gait training combined with functional electrical stimulation on recovery of locomotor mobility in chronic stroke patients: a randomized controlled trial. J Phys Ther Sci, 2014, 26: 1949-1953. [Medline] [CrossRef]

8) Hongshi L: In: The theory and practice of rehabilitation medicine. Shanghai: Science and Technology Hing House of Shanghai Press, 2000, pp 1313-1329. 